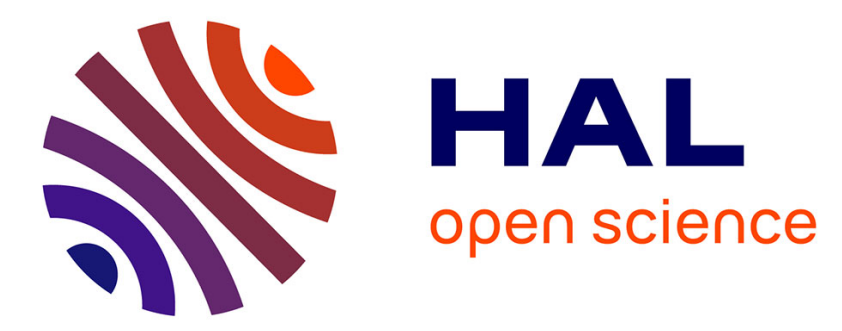

\title{
Nitridation enhancement of TiSi2 powders by addition of nickel
}

Jerome Roger, Laurine Nouvian, Yann Le Petitcorps, Laurence Maillé

\section{To cite this version:}

Jerome Roger, Laurine Nouvian, Yann Le Petitcorps, Laurence Maillé. Nitridation enhancement of TiSi2 powders by addition of nickel. Journal of Alloys and Compounds, 2017, 10.1016/j.jallcom.2017.07.031 . hal-01567344

\section{HAL Id: hal-01567344 \\ https://hal.science/hal-01567344}

Submitted on 22 Jul 2017

HAL is a multi-disciplinary open access archive for the deposit and dissemination of scientific research documents, whether they are published or not. The documents may come from teaching and research institutions in France or abroad, or from public or private research centers.
L'archive ouverte pluridisciplinaire HAL, est destinée au dépôt et à la diffusion de documents scientifiques de niveau recherche, publiés ou non, émanant des établissements d'enseignement et de recherche français ou étrangers, des laboratoires publics ou privés.

\section{(1) (1) $\$$}

Distributed under a Creative Commons Attribution - NonCommercial - NoDerivatives 44.0 


\title{
Nitridation enhancement of $\mathrm{TiSi}_{2}$ powders by addition of nickel
}

\author{
J. Roger ${ }^{\mathrm{a}, *}$, L. Nouvian ${ }^{\mathrm{a}}$, Y. Le Petitcorps ${ }^{\mathrm{a}}$, L. Maillé \\ ${ }^{a}$ Université de Bordeaux, CNRS, Laboratoire des Composites ThermoStructuraux, \\ UMR 5801, 33600 Pessac, France \\ * Corresponding author: e-mail: jerome.roger@lcts.u-bordeaux.fr
}

\begin{abstract}
The nitridation enhancement of a $\mathrm{TiSi}_{2}$ powder by nickel addition was examined. The quantities of the added metal were comprised between 2.5 and $25 \mathrm{~mol} . \%$, the balance being $\mathrm{TiSi}_{2}$. The isothermal heat treatments were made at $1100^{\circ} \mathrm{C}$ for durations up to 40 hours under normal pressure and continuous flow of pure nitrogen. Comparing to pure $\mathrm{TiSi}_{2}$ powder, an improvement of the conversion in $\mathrm{TiN}$ and $\mathrm{Si}_{3} \mathrm{~N}_{4}$ is obtained for compositions containing $10.0 ; 12.5$ and $15.0 \mathrm{~mol} . \%$ of nickel. According to the quaternary Ti-Si-Ni-N phase diagram, nickel was found to form $\mathrm{Ni}_{4} \mathrm{Ti}_{4} \mathrm{Si}_{7}$ compound. Thermogravimetric analysis of these three compositions showed the existence of three successive stages during the conversion. First, an initiate reaction occurred with a very weak weight gain. Then, the second stage exhibited an acceleration of the weight gain. Those two stages are both controlled by nucleation and growth, as represented by the kinetic equation $[-\ln (1-\alpha)]^{1 / 2}=$ k.t. Finally, the reaction is limited by three-dimension diffusion, as represented by the kinetic equation: $\left[1-(1-\alpha)^{1 / 3}\right]^{2}=$ k.t. From this behavior, an activation mechanism is proposed.
\end{abstract}

Keywords: A. ceramics; B. Gas-liquid reactions; C. Catalysis; C. Kinetics; E. thermodynamic properties; D. Thermal analysis; 


\section{Introduction}

Materials based on silicon nitride are one of the more promising materials for use in hightemperature applications thanks to their high heat resistance, refractoriness, hardness, durability, thermal shock resistance, and chemical resistance. They have a high potential in the practical utilization not only as a structural material but also as a functional material. Understanding of the silicon nitridation process has evolved significantly over the past decades, and the effects of many of the reaction variables on the reaction kinetics and product morphology are well documented [1-18]. In addition to monolithic ceramics, some works have also focused on using reaction-bonded silicon nitride as a composite matrix [19,20]. But, this way requires long durations and temperatures that exceed $1400^{\circ} \mathrm{C}$. This is problematic for composite applications because the whiskers or fibers used as reinforcements could be degraded at elevated temperatures. The formation of $\mathrm{Si}_{3} \mathrm{~N}_{4}$ from pure silicon generates a low volume expansion of $22 \%$. So, full densification implies an initial powder compactness of about $82 \%$. This starting value is unrealistic and full densification is then not possible by this way. An alternative possibility is to use an intermetallic compound as $\mathrm{TiSi}_{2}$. Indeed, the reaction to form $\mathrm{Si}_{3} \mathrm{~N}_{4}$ - $\mathrm{TiN}$ composite from $\mathrm{TiSi}_{2}$ is accompanied by a $60 \%$ volume expansion which occurs in the void space of the compact, such that complete nitridation should fully densified a $62.5 \%$ dense $\mathrm{TiSi}_{2}$ body. Titanium nitride is an interesting compound which is widely used to prepare metal ceramic, cutting tools, molds, coatings because of its high strength, high hardness, thermal stability, high electrical conductivity, good wear and corrosion resistance. The conventional synthesis of $\mathrm{TiN}$ involves direct nitridation, laser cladding, self propagating high-temperature synthesis and mechanical milling [21,22]. The combustion synthesis of TiN was investigated by several authors and was found relatively easy to proceed [23-27]. M. Ade and J. Haußelt [28] reported that the maximum conversion $(90 \%)$ of a pure $\mathrm{TiSi}_{2}$ powder with a mean grain size less than $2 \mu \mathrm{m}$ was obtained for a temperature close to $1400^{\circ} \mathrm{C}$, probably because of the formation of liquid silicon 
$\left(\mathrm{T}_{\text {melting }}(\mathrm{Si})=1414^{\circ} \mathrm{C}\right)$. The exothermicity of this reaction and the formation of liquid silicon could be detrimental in the case of fibrous composites. In a previous work, we focused our attention on the nitridation of pure $\mathrm{TiSi}_{2}$ compacts at lower temperatures $\left(1000-1200^{\circ} \mathrm{C}\right)$ to produce the matrix of a fibers-reinforced composite [29]. Accordingly to previous papers [3033], it was found that the nitridation is sluggish in these conditions because of diffusional limitations. Indeed, the titanium nitridation is easily but silicon reacts very slowly due to the formation of a TiN layer at the surface of the grains. This TiN layer behaves as a diffusion barrier towards nitrogen and silicon [30,31,34]. To circumvent this pitfall, it is required to set up a strategy to enhance the nitridation of $\mathrm{TiSi}_{2}$, this is the objective of the present work. It has been known that transition metals can regulate kinetics of silicon nitridation as well as the phases formation [3,12,35-37]. Since sintering additives are always used in the fabrication of materials from silicon nitride powder, the nitridation enhancement role of minor additions of common metals in the starting Si powder is well established [12,35,36,38-41]. Especially, it was shown that $\mathrm{Fe}, \mathrm{Ni}$ or $\mathrm{Al}$ addition promotes the formation of nitrides [36-38]. These metals should promote the crystallization and the disruption of the amorphous native silica layer located at the surface of the grains. Another explanation suggested that metals form a liquid phase by reacting with silicon to form a eutectic. On this way, we examine the effect of adding a metal powder to a $\mathrm{TiSi}_{2}$ powder to improve nitridation. Several metals were considered to promote nitridation at a temperature as low as $1100^{\circ} \mathrm{C}$. Based on the hypothesis that the formation of a liquid phase should enhance atomic mobility and consequently nitridation rate, the attention was focused on nickel because of the low-temperature eutectic $\mathrm{NiSi}-\mathrm{NiSi}_{2}\left(956^{\circ} \mathrm{C}\right)$. In the present work, the synthesis of $\mathrm{Si}_{3} \mathrm{~N}_{4}$-TiN-based composite has been studied by the nitridation of $\mathrm{TiSi}_{2}$ and $\mathrm{Ni}$ powders mixtures under nitrogen atmosphere.

\section{Thermodynamic analysis of the Ti-Si-Ni-N system equilibrium}

Prior to experimental investigation, a preliminary thermodynamic analysis of the equilibrium in the Ti-Si-Ni-N system was performed with the help of the ThermoCalc software [42]. The 
relevant thermodynamic descriptions of the Ti-Si-N and Ti-Si-Ni systems reported by $\mathrm{S}$. Sambasivan et al. and T. Tokunaga et al., respectively, were used for these calculations $[43,44]$. The so-calculated equilibrium diagrams at $1100^{\circ} \mathrm{C}$ are shown in Figure 1a and Figure 1b. The particularity of the Ti-Si-Ni system is the formation of a Si-rich ternary liquid phase at this temperature. This liquid phase originates from the $\mathrm{NiSi}-\mathrm{NiSi}_{2}$ eutectic reaction at only $956^{\circ} \mathrm{C}$, as shown in Figure 2 [45]. The phases stability diagrams for the (1-x) $\mathrm{TiSi}_{2}+x \mathrm{Ni}$ mixtures were calculated as a function of nitrogen content at $1100^{\circ} \mathrm{C}$ for $x=0.025 ; 0.100$; 0.150 and 0.250 . The so-obtained diagrams are shown in Figure 3. In each case, the formation of $\mathrm{TiN}$ and $\mathrm{Si}_{3} \mathrm{~N}_{4}$ nitrides is announced. Depending on the nitrogen quantity, nickel generates first the ternary compound $\mathrm{Ni}_{4} \mathrm{Ti}_{4} \mathrm{Si}_{7}$, then the ternary liquid and finally binary nickel silicides in equilibrium with gaseous nitrogen. This means that the formation of the liquid phase is possible at the interface with the atmosphere, what is favorable to nitrides formation by improving atomic diffusion. When looking at the variation of the nickel activity versus nitrogen content shown in Figure 4-a, one note that the lower Ni-activity value corresponds to the $\mathrm{TiN}+\mathrm{Si}_{3} \mathrm{~N}_{4}+\mathrm{Ni}_{4} \mathrm{Ti}_{4} \mathrm{Si}_{7}+\mathrm{TiSi}_{2}$ and $\mathrm{TiN}+\mathrm{Si}_{3} \mathrm{~N}_{4}+\mathrm{Ni}_{4} \mathrm{Ti}_{4} \mathrm{Si}_{7}$ equilibriums. So, one could expect that the equilibrium $\mathrm{TiN}+\mathrm{Si}_{3} \mathrm{~N}_{4}+\mathrm{Ni}_{4} \mathrm{Ti}_{4} \mathrm{Si}_{7}$ should be favored as a further nidridation implies an increase of nickel activity whereas nitrogen activity increases during the conversion (Figure 4-b). The expected reaction is (Reaction 1):

$\mathrm{TiSi}_{2}+x \mathrm{Ni}+\left(\frac{11}{6}-\frac{5}{3} \cdot x\right) \mathrm{N}_{2} \Rightarrow(1-x) \mathrm{TiN}+\left(\frac{2}{3}-\frac{7}{12} \cdot x\right) \mathrm{Si}_{3} \mathrm{~N}_{4}+\left(\frac{x}{4}\right) \mathrm{Ni}_{4} \mathrm{Ti}_{4} \mathrm{Si}_{7}$

The Gibbs free energy that varies with the progress of this reaction was also calculated. This reaction is favorable as it implies a large negative Gibbs free energy and decreases with the progress of the reaction as shown in Figure 5.

\section{Materials and experimental procedures}

The starting $\mathrm{TiSi}_{2}$ powder $\left(99.95 \%, d_{50}=44 \mu \mathrm{m}\right.$, Neyco) used in these experiments was analyzed by spectrographic analysis (S.C.A.-C.N.R.S., Villeurbanne, France) to determine the 
impurities content: $1.64 \% \mathrm{O}, 0.43 \% \mathrm{C}$ and $0.48 \% \mathrm{Fe}$ in mass. The nickel powder was supplied by Strem Chemicals $\left(99.9 \%, d_{50}=5 \mu \mathrm{m}\right)$. The two raw powders were milled together during 1 hour in ethanol with a vibratory mixer mill (Retsch MM200) (WC-milling-bowl and -balls) to reduce the grain size to $d_{50}=3-4 \mu \mathrm{m}$. The mean grain size of the powders was determined with the help of a Fritsch Analysette 22 Nanotec Plus granulometric analyser. The compositions of the powder mixtures are listed in Table 1. A part of each milled preparation was isostatically pressed to form a $10 \mathrm{~mm}$ diameter pellet. The green density was closed to $50 \%$ of theoretical. The pellets, weighing about $1 \mathrm{~g}$ each, were put into an alumina boat and were separated each other by alumina splitters (Figure 6). The nidridation reaction of these samples was performed in a horizontal quartz-tube furnace at $1100^{\circ} \mathrm{C}$ up to 40 hours in the presence of titanium powder as a getter. Mass variation measurements versus time were also performed in a thermogravimetric analyzer (Setaram TAG24) from $20^{\circ} \mathrm{C}$ to the treatment temperature at a heating rate of $10^{\circ} \mathrm{C} / \mathrm{min}$ for various durations up to 20 hours. TGA measurements were limited to this duration because of technical limitations due to the volatility of silicon. Nitridation processes were realized at normal pressure under a continuous nitrogen gas flow $(50 \mathrm{~mL} / \mathrm{min})$. The powder masses used for thermogravimetric analysis were comprised between 100 and $110 \mathrm{mg}$ for each sample, the mass conversion degree $(\alpha)$ of reaction at a time $t$ was estimated according to Equation 1:

$$
\alpha=\frac{\left(w_{i}-w_{0}\right)}{\left(w_{f}-w_{0}\right)}
$$

where $w_{0}, w_{\mathrm{i}}, w_{\mathrm{f}}$ are the initial, intermediate and final sample masses for complete conversion of $\mathrm{TiSi}_{2}$ in $\mathrm{TiN}, \mathrm{Si}_{3} \mathrm{~N}_{4}$ and $\mathrm{Ni}_{4} \mathrm{Ti}_{4} \mathrm{Si}_{7}$ phases. XRD experiments in Bragg-Brentano geometry were performed with a Bruker D8 Advance diffractometer using a $\mathrm{Cu} \mathrm{K} \alpha$ radiation fitted with a one-dimensional position sensitive silicon strip detector (Bruker, Linxeye). XRD patterns were recorded using a step size of $0.01^{\circ}$ for $2 \theta$ range $10-90^{\circ}$ and a counting time of 0.3 second per step. Sections of nitrided grains were prepared using ion polishing system (Cross Polisher JEOL Ltd.). These sections were observed with a FEI Quanta 400 FEG scanning 
electron microscope whereas the chemical composition was analyzed by EDX (EDAX Genesis XM4), operated at $5 \mathrm{kV}$ (interaction volume of roughly $150 \mathrm{~nm}$ wide in this condition).

\section{Results and discussion}

\subsection{Effect of nickel addition on TiSi $_{2}$ nitridation}

The results regarding the effects of nickel content in $(1-x) \mathrm{TiSi}_{2}+x$ Ni mixtures for $0.000 \leq x$ $\leq 0.250$ by step of 0.025 or 0.050 on the overall conversion at $1100^{\circ} \mathrm{C}$ are reported in Table 1 . It is clearly indicated that the addition of nickel investigated results in higher contents of TiN and $\mathrm{Si}_{3} \mathrm{~N}_{4}$ nitrides than obtained from pure $\mathrm{TiSi}_{2}$ powders. However, the overall mass conversion increases with nickel content up to $x=0.150$. The conversion is decreased when higher nickel fractions are added to the $\mathrm{TiSi}_{2}$ powder because large quantity of this metal hinders the gas diffusion and the nitridation of $\mathrm{TiSi}_{2}$. Moreover, the phases composing the compacts after nitridation depend on the nickel content. It is found from Table 1 that for nickel contents lower than 0.100 , nitridation is uncompleted as remaining $\mathrm{TiSi}_{2}$ and free silicon are detected; the ternary compound $\mathrm{Ni}_{4} \mathrm{Ti}_{4} \mathrm{Si}_{7}$ being however formed. In these cases, the nickel content is insufficient to rapidly and completely convert the powder. When the nickel content is larger than $0.150, \mathrm{TiSi}_{2}$ and free silicon are no more detected but undesired nickel silicides are obtained. In this situation, it is confirmed that the nickel quantity is too high. Consequently, the appropriate quantity of nickel $x$ is comprised between 0.100 and 0.150. X-ray diffraction experiments of the samples with $x=0.100$ (Figure 7), $x=0.125$ or $x$ $=0.150$ showed that the final phase composition is $\mathrm{TiN}, \alpha-\mathrm{Si}_{3} \mathrm{~N}_{4}, \beta-\mathrm{Si}_{3} \mathrm{~N}_{4}$ and $\mathrm{Ni}_{4} \mathrm{Ti}_{4} \mathrm{Si}_{7}$. The morphologies of the resulting nitrided compacts are similar for theses three compositions. On the micrographies of the mixture with $x=0.125$ (Figure 8), one can note the homogeneity of the phases dispersion, the absence of cracks and the smallness of the produced grains. The starting porosity was close to $50 \%$ whereas the final porosity is of about $25 \%$, the volumes of 
the compacts being unchanged. The results of the nitridation experiments agree partially with the calculated thermodynamic equilibriums exposed herein for $x=0.025 ; 0.100 ; 0.150$ and 0.250 (Figures 3,4,5). Indeed, in all cases, the thermodynamic calculations for an excess of nitrogen predict the formation of $\mathrm{TiN}, \mathrm{Si}_{3} \mathrm{~N}_{4}$ and $\mathrm{Ni}_{5} \mathrm{Si}_{2}$. The experimentally formed phases do not strictly correspond to this calculated state. From Table 1, one note that the nitrides are effectively generated as expected but $\mathrm{Ni}_{5} \mathrm{Si}_{2}$ is in no case formed. This partial unreliability of the calculations is attributable to the fact that the conversion reaction occurs only at the interface between $\mathrm{TiSi}_{2}$ and the gaseous nitrogen. Nickel particles are located at the surface of the $\mathrm{TiSi}_{2}$ grains and despite the milling stage; these metal particles are unlikely dispersed in a perfectly homogeneous way. The consequence is a partial improvement of the conversion for weak nickel contents $(x \leq 0.075)$ with remaining $\mathrm{TiSi}_{2}$ and free silicon. In contrast, these two last phases are no more detected for high nickel contents $(x \geq 0.175)$ but $\mathrm{NiSi}$ and $\mathrm{NiSi}_{2}$ are generated. In this case, the nickel particles may be locally concentrated and promote the formation of large amounts of liquid which solidified in forming these nickel silicides and maybe of others undetected phases. The hypothesis is confirmed by the decrease of the conversion rate when increasing nickel content because of the filling of the porosities by the liquid inducing a limitation of gaseous diffusion preventing the conversion. For $0.100 \leq x \leq$ 0.150 , the final phases are $\mathrm{TiN}, \mathrm{Si}_{3} \mathrm{~N}_{4}$ and $\mathrm{Ni}_{4} \mathrm{Ti}_{4} \mathrm{Si}_{7}$. This promising equilibrium state was expected from thermodynamic considerations and it is experimentally generated with conversion percentages of at least $90 \%$. $\mathrm{Ni}_{4} \mathrm{Ti}_{4} \mathrm{Si}_{7}$ stabilization is improved because of the probable gradual reduction of the interactions between this ternary phase and nitrogen due to the protective effect induced by the surrounding nitrides crust. The kinetics and the conversion mechanism were subsequently examined for the three retained compositions $(1-x)$ $\mathrm{TiSi}_{2}+x \mathrm{Ni}$ corresponding to $x=0.100 ; 0.125$ and 0.150 . 


\subsection{Thermogravimetric analysis and reaction mechanism}

The thermogravimetric curves of two samples of pure $\mathrm{TiSi}_{2}$ powders $\left(d_{50}=1.4\right.$ and $\left.4.5 \mu \mathrm{m}\right)$ and three samples of $(1-x) \mathrm{TiSi}_{2}+x$ Ni mixtures $(x=0.100 ; 0.125$ and 0.150$)$ reacting with $\mathrm{N}_{2}$ were measured at $1100^{\circ} \mathrm{C}$ until durations close to 20 hours. According to Equation 1 and Reaction 1, the relationship between the conversion degree and the time is shown in Figure 9. In all cases, the conversion percentages tended to increase with rising reaction duration. The achieved degrees of conversion after 17 hours were found equal to $88.7 \%, 92.8 \%$ and $92.9 \%$ for the $(1-x) \mathrm{TiSi}_{2}+x \mathrm{Ni}$ mixtures with $x=0.100 ; 0.125$ and 0.150 , respectively. The corresponding percentages for pure $\mathrm{TiSi}_{2}$ powders are significantly lower as equal to $43.3 \%$ and $51.9 \%$ for $d_{50}=4.5 \mu \mathrm{m}$ and $1.4 \mu \mathrm{m}$, respectively. The kinetic models of the solid-state reactions are basically divided into three main categories: 1) models in which the reaction rate is determined by nucleation and growth; 2) the models in which the controlling step is the diffusion of reactants or diffusional models; 3 ) models in which the administered mechanism is the chemical reaction at the interphase of the reactant-product [46]. The most appropriate kinetic models are listed in Table 2. Fitting the experimental data to the corresponding kinetic model functions $g(\alpha)=k . t$ involves nucleation-growth, chemical reaction and diffusion. So, the best fitting $k$ coefficient represents the specific reaction mechanism. In this study, the three $(1-x) \mathrm{TiSi}_{2}+x$ Ni mixtures $(x=0.100 ; 0.125$ and 0.150$)$ were found to have the same three successive stages during nitridation. For the first stage, the best fitting function was identified as the $A 2$ nucleation-growth model with a weak weight gain. For the second stage, the best fitting function was also the $A 2$ nucleation-growth model with a strong increase of the weight gain for a short duration. The third stage was found to be described by the $D 3$ threedimensional diffusion model for a spherical symmetry. Data fitting of the selected model functions for the three stages is shown in Figure 10. This method provides a reaction mechanism for the whole process of $\mathrm{TiN}, \mathrm{Si}_{3} \mathrm{~N}_{4}$ and $\mathrm{Ni}_{4} \mathrm{Ti}_{4} \mathrm{Si}_{7}$ synthesis. The nitridation reaction of a $\mathrm{TiSi}_{2}$ powder activated by addition of nickel can be summarized by three successive stages associated to three specific kinetics coefficients $k_{1}, k_{2}$ and $k_{3}$ as follows:

1) $\mathrm{TiSi}_{2}$ and nickel powders react and form $\mathrm{Ni}_{4} \mathrm{Ti}_{4} \mathrm{Si}_{7}$. This ternary phase begins to react with nitrogen and generates $\mathrm{TiN}, \mathrm{Si}_{3} \mathrm{~N}_{4}$ and a low quantity of a ternary liquid with a weak weight gain (step (1) in Figure 9 and Figure 11-a);

2) the increase of the liquid quantity promotes the rapid nucleation and growth of TiN and $\mathrm{Si}_{3} \mathrm{~N}_{4}$ grains up to forming a nitrided layer (step (2) in Figure 9 and Figure 11-a); 
3) the gas transfer through the product layer implies a diffusion limitation until full nitridation (step (3) in Figure 9 and Figure 11-a).

This mechanism is evidenced by the micrograph of the Figure 11-b since it shows a large grain exhibiting the phases sequence $\mathrm{TiN}+\mathrm{Si}_{3} \mathrm{~N}_{4} /(\mathrm{Si}, \mathrm{Ni}, \mathrm{Ti}) \mathrm{Liquid} / \mathrm{Ni}_{4} \mathrm{Ti}_{4} \mathrm{Si}_{7} / \mathrm{TiSi}_{2}$. In a previous study, we reported the assumption that the nitridation of pure $\mathrm{TiSi}_{2}$ powders with close mean grain size can be described by two successive steps. During the first step, only TiN is formed and generates a layer that behaves as a diffusion barrier limiting silicon nitridation. The second step occurs after significantly longer exposures and involves a sluggish nitridation of silicon at the center of the $\mathrm{TiSi}_{2}$ grain thanks to the formation of opened porosities generated by the Kirkendall effect [29]. This mechanism slows down the progress of the reaction so that the nitridation kinetics are very low and the conversion is inadequate. In the present case, the addition of metallic nickel to $\mathrm{TiSi}_{2}$ powder modified the nitridation mechanism to such an extent that full nitridation is substantially reached. The efficiency of nickel addition on the conversion is clearly demonstrated. The kinetic deceleration for conversion percentages larger than $80 \%$ visible in Figure 9 is presumably induced by an enlargement of the necks between the grains and by the reduction of the porosity which limit all the more the gaseous diffusion. When comparing the slops of the curves corresponding to the $k$ kinetic coefficients, the highest values are found with $x=0.125$ for the three stages $\left(k_{1}^{0.125}=0.18 \mathrm{~h}^{-1}, k_{2}{ }^{0.125}=0.53 \mathrm{~h}^{-1}, k_{3}{ }^{0.125}=0.022 \mathrm{~h}^{-1}\right)$ (Figure 10). The $k$ coefficients for $x=0.150$ have intermediate values with $k_{1}^{0.150}=0.15 \mathrm{~h}^{-1}, k_{2}^{0.150}=0.41 \mathrm{~h}^{-1}$, $k_{3}{ }^{0.150}=0.024 \mathrm{~h}^{-1}$. The $k$ values of the two first stages for $x=0.100$ are close to an half of the values for $x=0.125$ and 0.150 i.e. $k_{1}^{0.100}=0.087 \mathrm{~h}^{-1}, k_{2}{ }^{0.100}=0.27 \mathrm{~h}^{-1}$. The $k_{3}^{0.100}$ coefficient of the third stage for $x=0.100$ is equal to $0.020 \mathrm{~h}^{-1}$, this value is close but slightly lowest than the corresponding coefficients for $x=0.125$ and 0.150 i.e. $k_{3}^{0.125}=0.022 \mathrm{~h}^{-1}$ and $k_{3}{ }^{0.150}=$ $0.024 \mathrm{~h}^{-1}$. Finally, the global highest kinetic is attributed for $x=0.125$. An intermediate but close global kinetic is obtained with $x=0.150$ and the slowest global kinetic is associated to $x$ $=0.100$. The slowest kinetics measured for this composition can be justified by a lower 
content of nickel which consequently generates a lower quantity of liquid. The quantity of liquid blatantly influences the conversion kinetic. On the other hand, the kinetic progression of the conversion for $x=0.150$ is close but slightly slower than the one with $x=0.125$ despite a more elevated nickel content. This behavior is probably induced by the formation of a larger content of the $\mathrm{Ni}_{4} \mathrm{Ti}_{4} \mathrm{Si}_{7}$ compound. However, the conversion percentages move towards comparable values of about $90 \%$. When considering the theoretical volume increase during the nitridation (Table 1), the most interesting composition corresponds to $x=0.100$ as the corresponding volume gain is the most elevated. Despite a slower conversion kinetic, this composition is the most interesting to obtain the highest densification effect. TiSi $i_{2}$-metal samples containing $10 \mathrm{~mol} \%$ of iron or cobalt instead of nickel were also prepared and heat treated at $1100^{\circ} \mathrm{C}$ by applying a similar protocol. It was then found the formation of $\mathrm{Fe}_{4} \mathrm{Ti}_{4} \mathrm{Si}_{7}$ or $\mathrm{Co}_{4} \mathrm{Ti}_{4} \mathrm{Si}_{7}$, TiN and free silicon as shown in Figure 12. The weight gains are lower than pure $\mathrm{TiSi}_{2}$. The weak conversion rates obtained in these cases are justified by the absence of liquid phases in these systems at $1100^{\circ} \mathrm{C}$. So, the nitridation conversion is not enhanced and the ternary phase layers formed at the surface of the grains limit the nitrides formation. This demonstrates the essential role played by the formation of a liquid phase.

\section{Conclusion}

$\mathrm{TiSi}_{2}$ powders blended with nickel were nitrided in a stream of pure nitrogen at $1100^{\circ} \mathrm{C}$ to investigate the catalytic effect of metal addition on the direct nitridation. As expected from thermodynamic considerations, the nitridation of $\mathrm{TiSi}_{2}$ in the presence of metallic nickel generated the TiN, $\mathrm{Si}_{3} \mathrm{~N}_{4}$ and $\mathrm{Ni}_{4} \mathrm{Ti}_{4} \mathrm{Si}_{7}$ phases for the (1-x) $\mathrm{TiSi}_{2}+x$ Ni mixtures with $0.100 \leq$ $x \leq 0.150$. The conversion percentage is greatly enhanced within this composition range as the final values are around $90 \%$. It is suggested that the presence of liquid phase formed during the reaction is at the origin of the kinetic increase of the conversion. The whole reaction process includes three main stages. During the first stage, the weight gain is negligible as the 
controlling mechanism is the reaction between $\mathrm{TiSi}_{2}$ and nickel grains to form the $\mathrm{Ni}_{4} \mathrm{Ti}_{4} \mathrm{Si}_{7}$ compound. A very weak weight gain is however measured corresponding to a nucleation and growth limiting process resulting from the induction of the nitrides growth instigating the formation of the liquid phase. During the second stage, the nucleation and growth process of the nitrides phases is the limiting process controlling mechanism with an impressive increase of the kinetic. A deceleration of the kinetic coefficients is measured during the third stage because the conversion is limited by the three-dimensional gas transfer process due to the nitride layer thickening.

\section{Acknowledgement}

This work has been performed within the frame of the training of Brice Ripoche from ESIREM, Dijon, France. 


\section{References}

[1] A. Atkinson, P.J. Leatt, A.J. Mouslon, The role of nitrogen flow into the nitriding compact in the production of reaction-sintered silicon nitride, Proc. Brit. Ceram. Soc. 22 (1973) 253-274.

[2] H.M. Jennings, M.H. Richman, Structure, formation mechanisms and kinetics of reaction-bonded silicon nitride, J. Mater. Sci. 11(11) (1976) 2087-2098.

[3] H.M. Jennings, On reactions between silicon and nitrogen Part 1 Mechanisms, J. Mater. Sci. 18(4) (1983) 951-967.

[4] H. Kim, C.H. Kim, The effects of second-component gases on the transport properties of silicon nitriding atmosphere, J. Mater. Sci. Letters, 3 (1984) 199-200.

[5] C.E. Bouldin, E.A. Stern, M.S. Donley, T.G. Stoebe, Iron impurities in $\mathrm{Si}_{3} \mathrm{~N}_{4}$ processing, J. Mater. Sci. 20 (1985) 1807-1810.

[6] H. Kim, C.H. Kim, The influence of the various transport properties of the nitriding atmosphere on the formation of reaction-bonded $\mathrm{Si}_{3} \mathrm{~N}_{4}$, J. Mater. Sci. 20 (1985) 149156.

[7] W.R. Moser, D.S. Briere, R. Correia, G.A. Rossetti, Kinetics of iron-promoted silicon nitridation, J. Mater. Res. 1 (1986) 797-802.

[8] H.M. Jennings, B.J. Dalgleish, P.L. Pratt, Reactions between silicon and nitrogen: Part 2. Microstructure, J. Mater. Sci. 23(7) (1988) 2573-2583.

[9] G.A. Rossetti Jr, R.P. Denkewicz Jr, Kinetic interpretation of $\alpha$ - and $\beta-\mathrm{Si}_{3} \mathrm{~N}_{4}$ formation from oxide-free high-purity silicon powder, J. Mater. Sci. 24(9) (1989) 3081-3086.

[10] A. Varma, R.G. Pigeon, A.E. Miller, Kinetics of $\alpha$ - and $\beta-\mathrm{Si}_{3} \mathrm{~N}_{4}$ formation from oxide-free high-purity Si powder, J. Mater. Sci. 26(16) (1991) 4541-4544.

[11] R.G. Pigeon, A. Varma, Some chemical reaction engineering considerations in the synthesis of silicon nitride, Chem. Eng. Sci. 47(9-11) (1992) 2585-2590.

[12] R.G. Pigeon, A. Varma, A.E. Miller, Some factors influencing the formation of reactionbonded silicon nitride, J. Mater. Sci. 28 (1993) 1919-1936.

[13] B.W. Sheldon, J.R. Rankin, J.S. Haggerty, Formation of reaction-bonded silicon nitride from silane-derived silicon powders: nucleation and growth mechanisms, J. Am. Ceram. Soc. 78(6) (1995) 1624-1632.

[14] M. Maalmi, A. Varma, Intrinsic nitridation kinetics of high-purity silicon powder, AlChe Journal, 42 (1996) 3477-3483.

[15] M. Maalmi, A. Varma, W.C. Strieder, Reaction-bonded silicon nitride synthesis: experiments and model, Chem. Eng. Sci. 53(4) (1998) 679-689.

[16] F.W. Chang, T.H. Liou, F.M. Tsai, The nitridation kinetics of silicon powder compacts, Thermochimica Acta, 354 (2000) 71-80. 
[17] M.K. Kim, J.K. Park, H.W. Lee, S. Kang, A cyclic process for the nitridation of Si powder, Mater. Sci. Eng. A408(1-2) (2005) 85-91.

[18] F. Wang, X. Qin, G. Jin, X. Guo, Temperature-controlled synthesis of $\mathrm{Si}_{3} \mathrm{~N}_{4}$ nanomaterials via direct nitridation of Si powders, Physica, E42 (2010) 2033-2035.

[19] A.J. Moulson, Reaction-bonded silicon nitride: its formation and properties, J. Mater. Sci. 14 (1979) 1017-1051.

[20] R.T. Bhatt, R.E. Phillips, Thermal effects on the mechanical properties of SiC fibre reinforced reaction-bonded silicon nitride matrix composites, J. Mater. Sci. 25 (1990) 3401-3407.

[21] I. Brokhin, A. Fridman, The preparation and investigation of some titanium nitridemolybdenum cermets, Sov. Powder Metall. Met. Ceram. 4 (7) (1965) 545-550.

[22] Y.H. Hwang, C.I. Lin, Preparation of titanium nitride from direct nitridation of titanium, J. Chem. Eng. Jpn. 31 (2) (1998) 214-219.

[23] Z.A. Munir, J.B. Holt, The combustion synthesis of refractory nitrides: Part 1. Theoretical analysis, J. Mater. Sci. 22(2) (1987) 710-714.

[24] H. Rode, V. Hlavacek, Detailed kinetics of titanium nitride synthesis, AlChe J. 41(2) (1995) 377-388.

[25] A. Pivkina, P.J. van der Put, Yu. Frolov, J. Schoonman, Reaction-bonded titanium nitride ceramics, J. Eur. Ceram. Soc. 16(1) (1996) 35-42.

[26] A.S. Bolokang, M.J. Phasha, Formation of titanium nitride produced from nanocrystalline titanium powder under nitrogen atmosphere, Int. J. Refract. Met. Hard Mater. 28(5) (2010) 610-615.

[27] C. Li, X. Lv, J. Chen, X. Liu, C. Bai, Kinetics of titanium nitride synthesized with Ti and $\mathrm{N}_{2}$, Int. J. Refract. Met. Hard Mater. 52 (2015) 165-170.

[28] M. Ade, J. Haußelt, Electroconductive ceramic composites with low-to-zero shrinkage during sintering, J. Eur. Ceram. Soc. 23 (2003) 1979-1986.

[29] J. Roger, L. Maillé, M.A. Dourges, Isothermal nitridation kinetics of $\mathrm{TiSi}_{2}$ powders, J. Solid State Chem. 212 (2014) 134-140.

[30] M. Wittmer, Self-aligned diffusion barrier by nitridation of $\mathrm{TiSi}_{2}$, Appl. Phys. Lett. 52 (1988) 1573-1575.

[31] A. Kamgar, F.A. Baiocchi, A.B. Emerson, T.T. Sheng, M.J. Vasile, R.W. Haynes, Selfaligned TiN barrier formation by rapid thermal nitridation of $\mathrm{TiSi}_{2}$ in ammonia, J. Appl. Phys. 66 (1989) 2395-2401.

[32] J. Perez-Rigueiro, C. Jimenez, L. Vazquez, R. Perez-Casero, J.M. Martinez-Duart, Nitridation of $\mathrm{TiSi}_{2}$ thin films by rapid thermal processing, Surf. Coat. Technol. 80 (1996) 72-75. 
[33] J.C. Han, G.Q. Chen, S.Y. Du, J.V. Wood, Synthesis of $\mathrm{Si}_{3} \mathrm{~N}_{4}-\mathrm{TiN}-\mathrm{SiC}$ composites by combustion reaction under high nitrogen pressures, J. Eur. Ceram. Soc. 20 (2000) 927932.

[34] K.G. Grigorov, G.I. Grigorov, M. Stoyanova, J.L. Vignes, J.P. Langeron, P. Denjean, J. Perriere, Diffusion of Silicon in Titanium Nitride Films. Efficiency of TiN Barrier Layers, Appl. Phys. A55 (1992) 502-504.

[35] S.M. Boyer, A.J. Moulson, A mechanism for the nitridation of Fe-contaminated silicon, J. Mater. Sci. 13(8) (1978) 1637-1646.

[36] S.S. Lin, Comparative studies of metal additives on the nitridation of silicon, J. Am. Ceram. Soc. 60(1-2) (1977) 78-81.

[37] V. Pavarajarn, S. Kimura, Catalytic effects of metals on direct nitridation of silicon, J. Am. Ceram. Soc. 84(8) (2001) 1669-1674.

[38] M. Mitomo, Effect of Fe and Al additions on nitridation of silicon, J. Mater. Sci. 12(2) (1977) 273-276.

[39] C.G. Cofer, J.A. Lewis, Chromium catalysed silicon nitridation, J. Mater. Sci. 29(22) (1994) 5880-5886.

[40] V. Pavarajarn, T. Vongthavorn, P. Praserthdam, Enhancement of direct nitridation of silicon by common metals in silicon nitride processing, Ceram. Inter. 33(4) (2007) 675680.

[41] J. Huang, S. Zhang, Z. Huang, M. Fang, Y. Liu, K. Chen, Co-catalyzed nitridation of silicon and in-situ growth of $\alpha-\mathrm{Si}_{3} \mathrm{~N}_{4}$ nanorods, Ceram. Inter. B40(7) (2014) 11063-11070.

[42] J.O. Andersson, T. Helander, L. Höglund, P.F. Shi, B. Sundman, Thermo-Calc and DICTRA, Computational tools for materials science, Calphad, 26 (2002) 273-312.

[43] S. Sambasivan, W.T. Petuskey, Phase chemistry in the Ti-Si-N system : Thermochemical review with phase stability diagrams, J. Mater. Res. 9 (1994) 2362-2369.

[44] T. Tokunaga, K. Hashima, H. Ohtani, M. Hasebe, Thermodynamic analysis of the Ni-Si-Ti system using thermochemical properties determined from ab initio calculations, Mater. Trans. 45(5) (2004) 1507-1514.

[45] T. Tokunaga, K. Nishio, H. Ohtani, M. Hasebe, Thermodynamic assessment of the Ni-Si system by incorporating ab initio energetic calculations into the CALPHAD approach, Calphad, 27(2) (2003) 161-168.

[46] J. Hancock, J. Sharp, Method of comparing solid-state kinetic data and its application to the decomposition of kaolinite, brucite, and $\mathrm{BaCO}_{3}, \mathrm{~J}$. Am. Ceram. Soc. 55 (2) (1972) 74-77. 


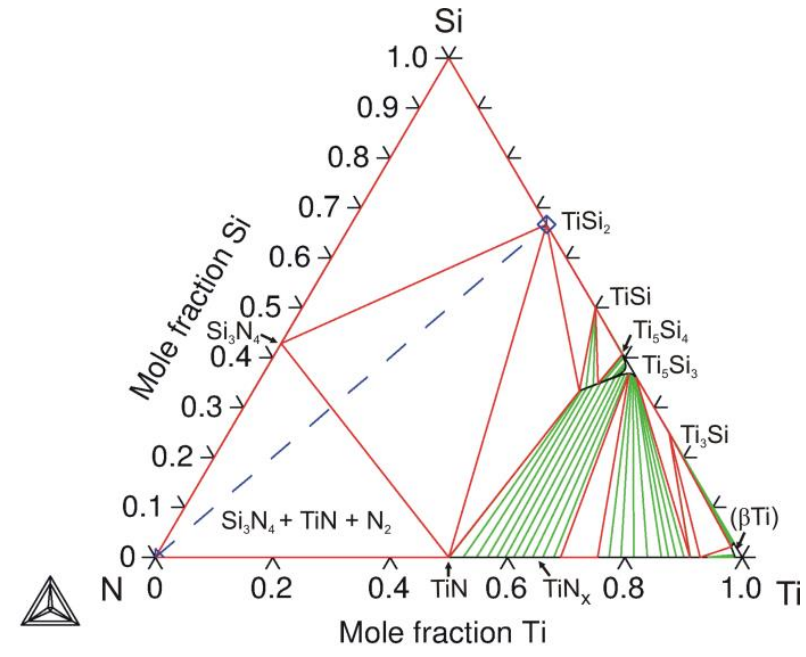

a)

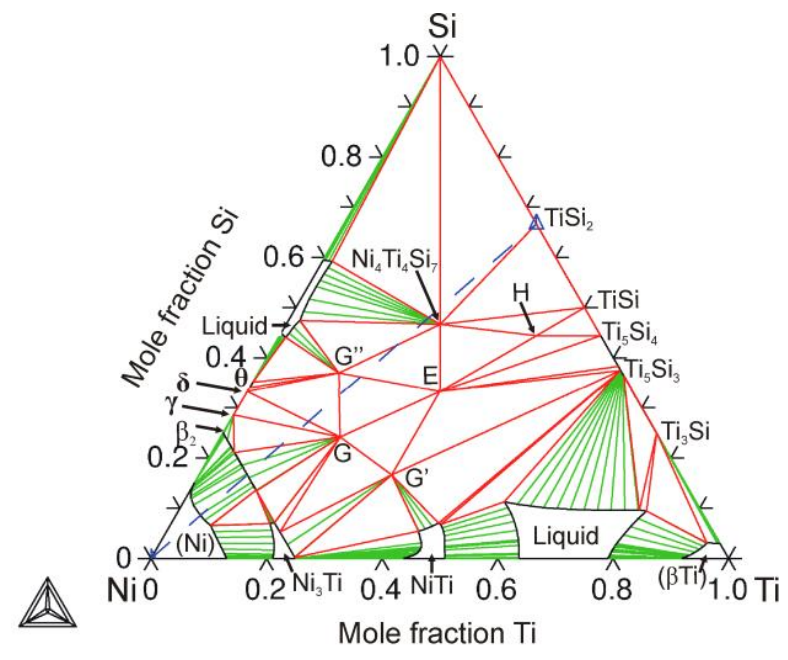

b)

Figure 1: Equilibrium diagrams simulated at $1100^{\circ} \mathrm{C}$ with ThermoCalc software [42]: a) N-Ti-Si [43] and b) Ni-Ti-Si [44].

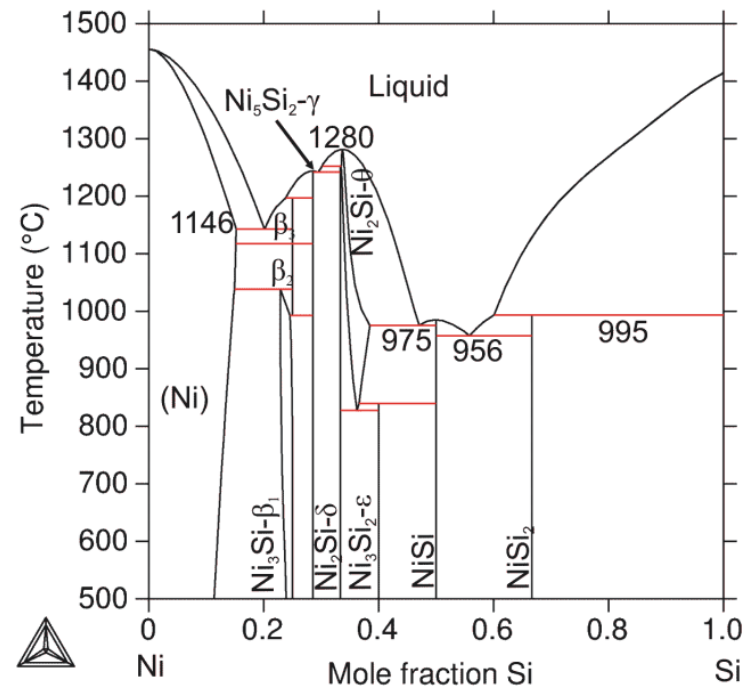

Figure 2: Ni-Si phases diagram simulated with ThermoCalc software $[42,45]$. 


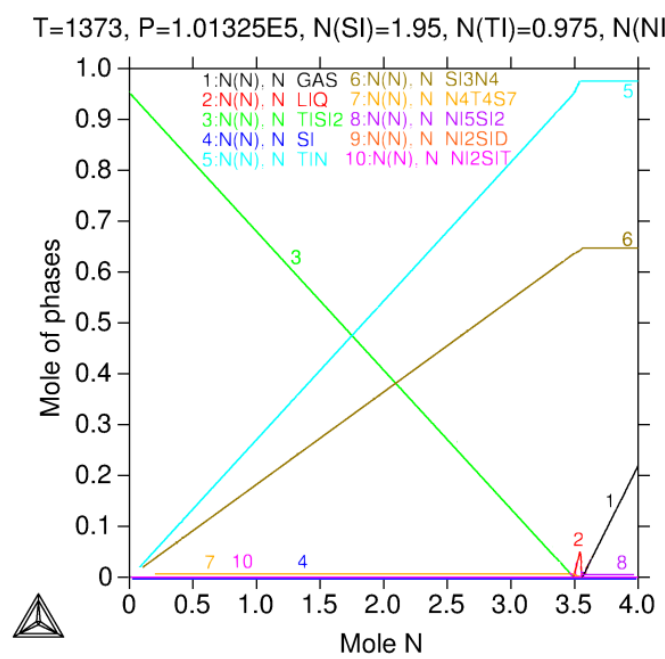

a)

$T=1373, P=1.01325 E 5, N(S I)=1.7, N(T I)=0.85, N(N I)=0.15$;

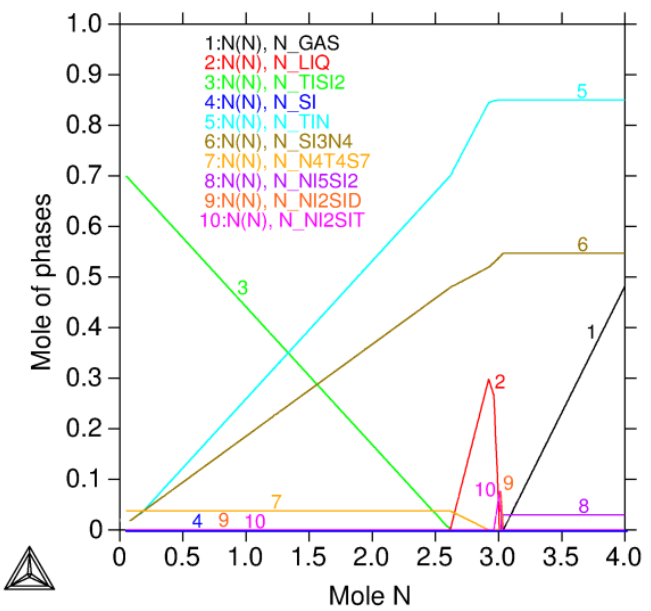

c)

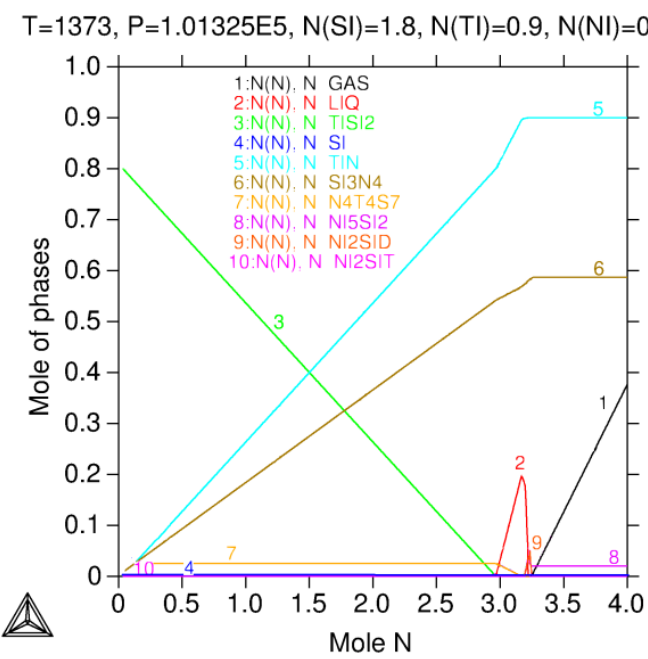

b)

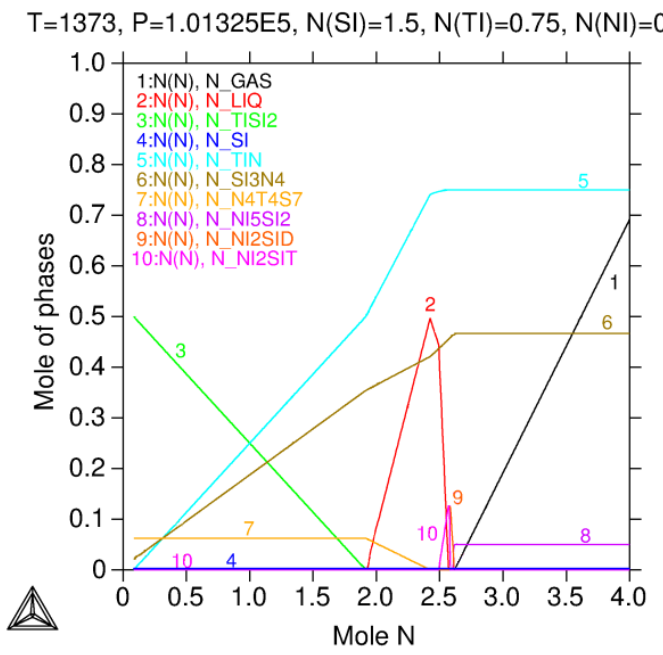

d)

Figure 3: Thermodynamic stability of $(1-x) \mathrm{TiSi}_{2}+x \mathrm{Ni}(x=0.025 ; 0.100 ; 0.150$ and 0.250$)$ versus nitrogen content system at $1100^{\circ} \mathrm{C}$ simulated with ThermoCalc software [42-44]

$\left(\mathrm{N} 4 \mathrm{~T} 4 \mathrm{~S} 7=\mathrm{Ni}_{4} \mathrm{Ti}_{4} \mathrm{Si}_{7}, \mathrm{Ni} 2 \mathrm{SiD}=\mathrm{Ni}_{2} \mathrm{Si}-\delta, \mathrm{Ni} 2 \mathrm{SiT}=\mathrm{Ni}_{2} \mathrm{Si}-\theta\right)$ 


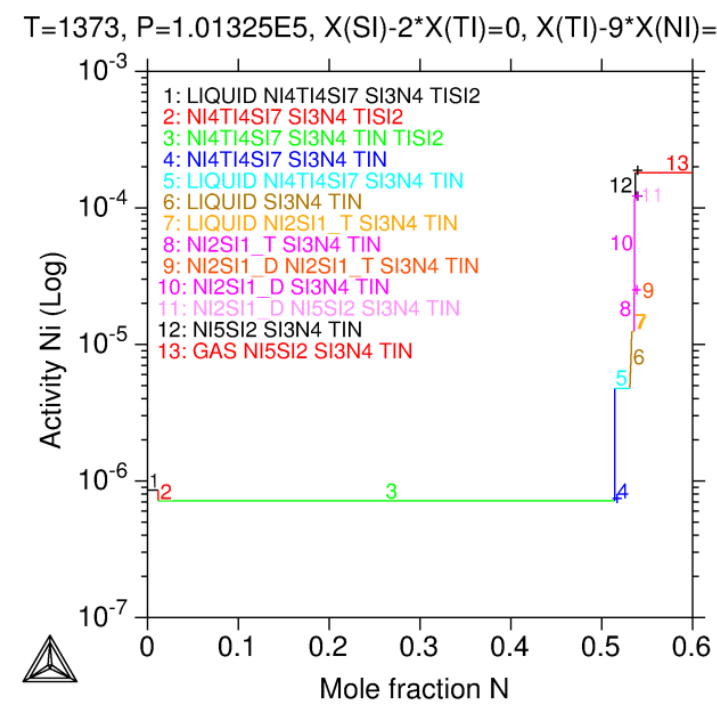

a)

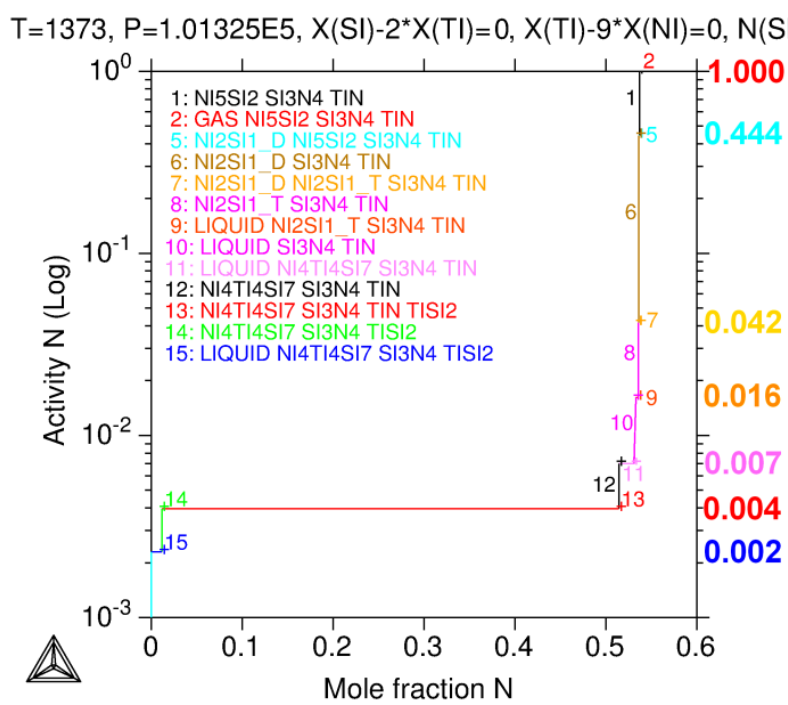

b)

Figure 4: Nitridation of the $0.900 \mathrm{TiSi}_{2}+0.100 \mathrm{Ni}$ mixture at $1100^{\circ} \mathrm{C}$ :

a) variation of nitrogen activity et b) variation of nickel activity

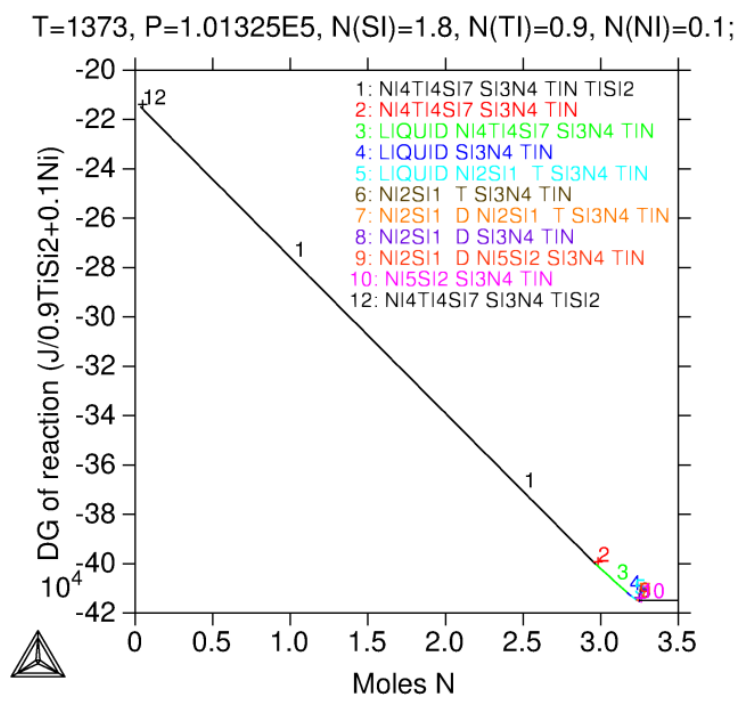

Figure 5: Gibbs free energy variation during the nitridation reaction of the $0.900 \mathrm{TiSi}_{2}+0.100 \mathrm{Ni}$ composition at $1100^{\circ} \mathrm{C}$

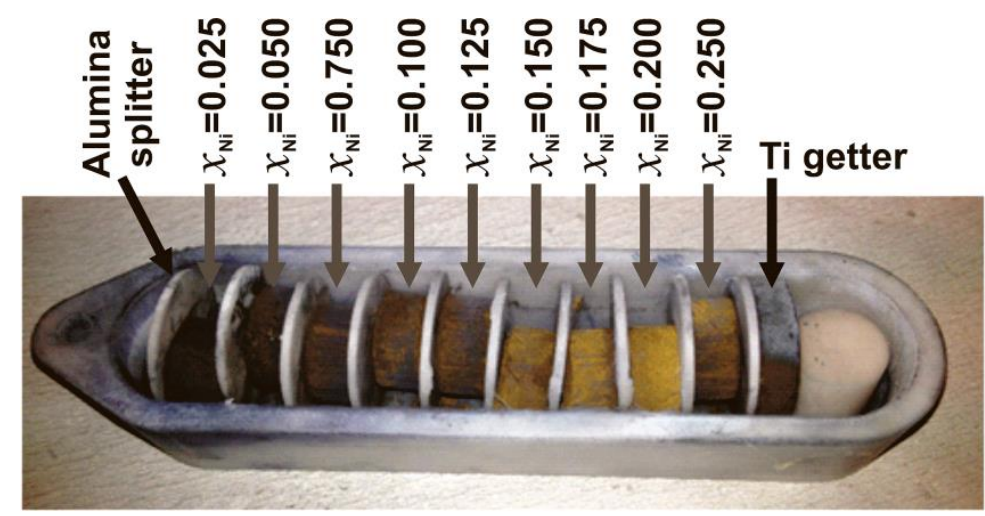

Figure 6: Samples $(1-x) \mathrm{TiSi}_{2}+x$ Ni mixtures with $0.025 \leq x \leq 0.250$ after nitridation at $1100^{\circ} \mathrm{C}$ during 40 hours 


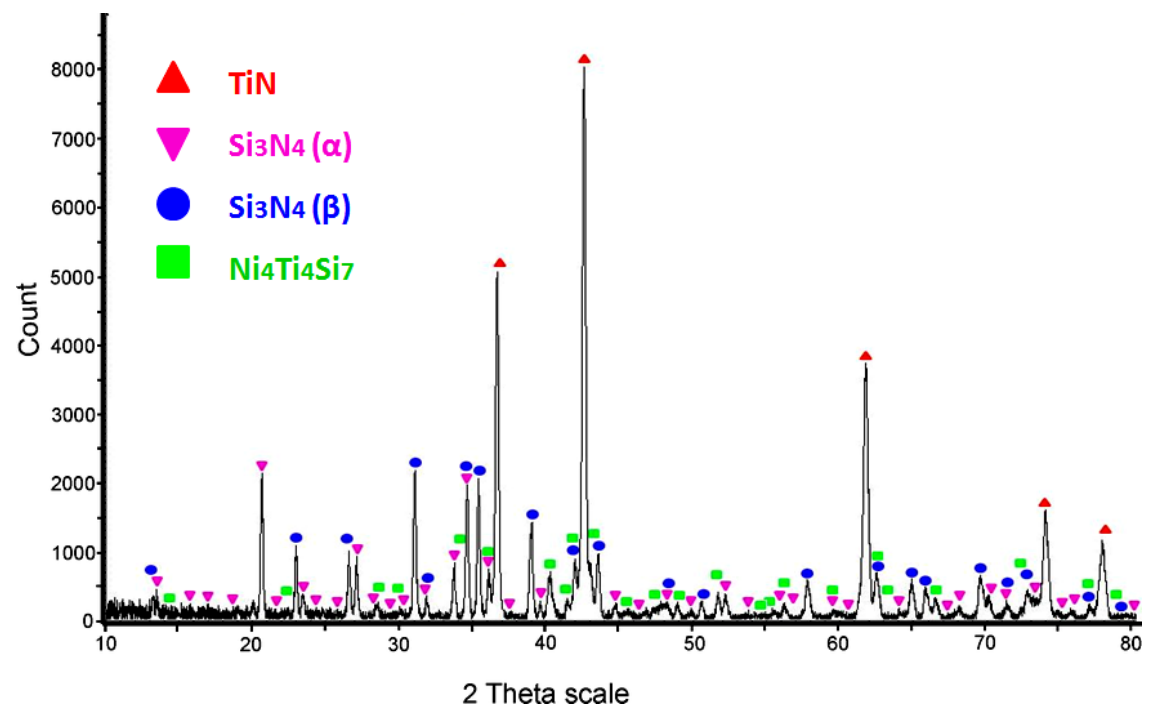

Figure 7: X-ray powder diffraction pattern of the $0.900 \mathrm{TiSi}_{2}+0.100 \mathrm{Ni}$ composition nitrided at $1100^{\circ} \mathrm{C}$ for 40 hours

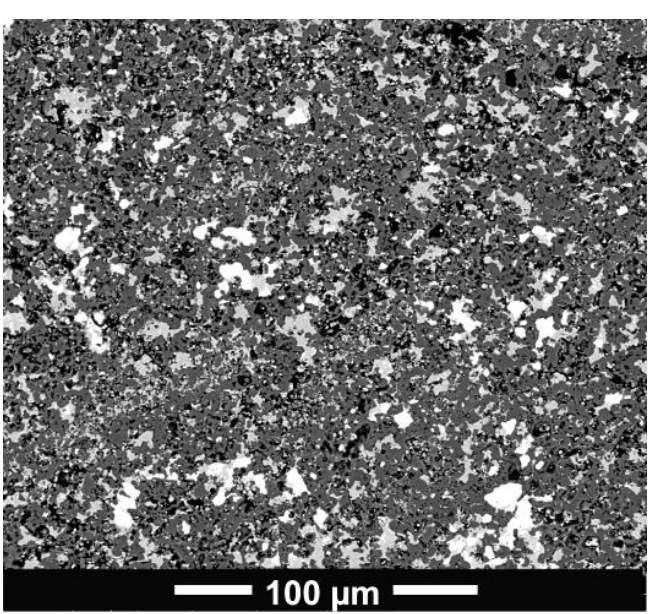

a)

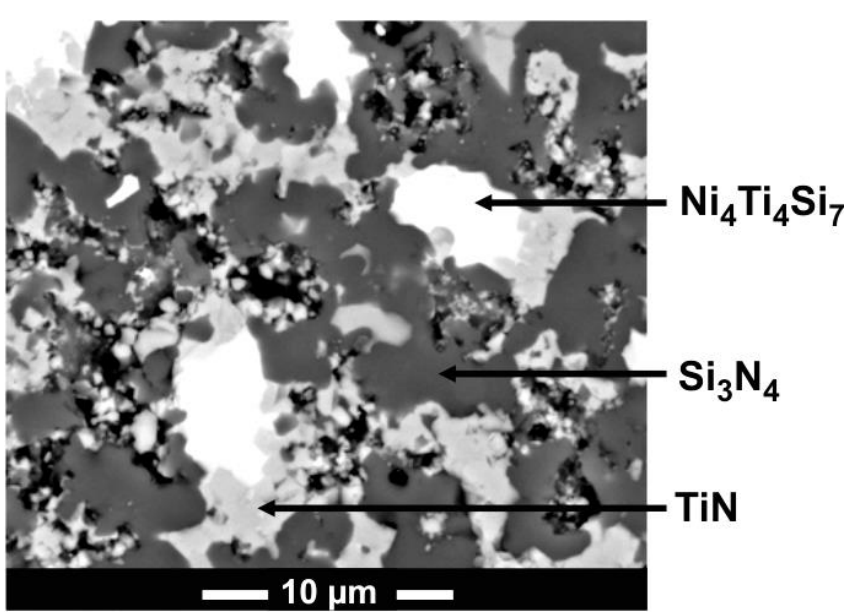

b)

Figure 8: Backscattered electrons images of the $0.875 \mathrm{TiSi}_{2}+0.125 \mathrm{Ni}$ composition treated at $1100^{\circ} \mathrm{C}$ for 40 hours 


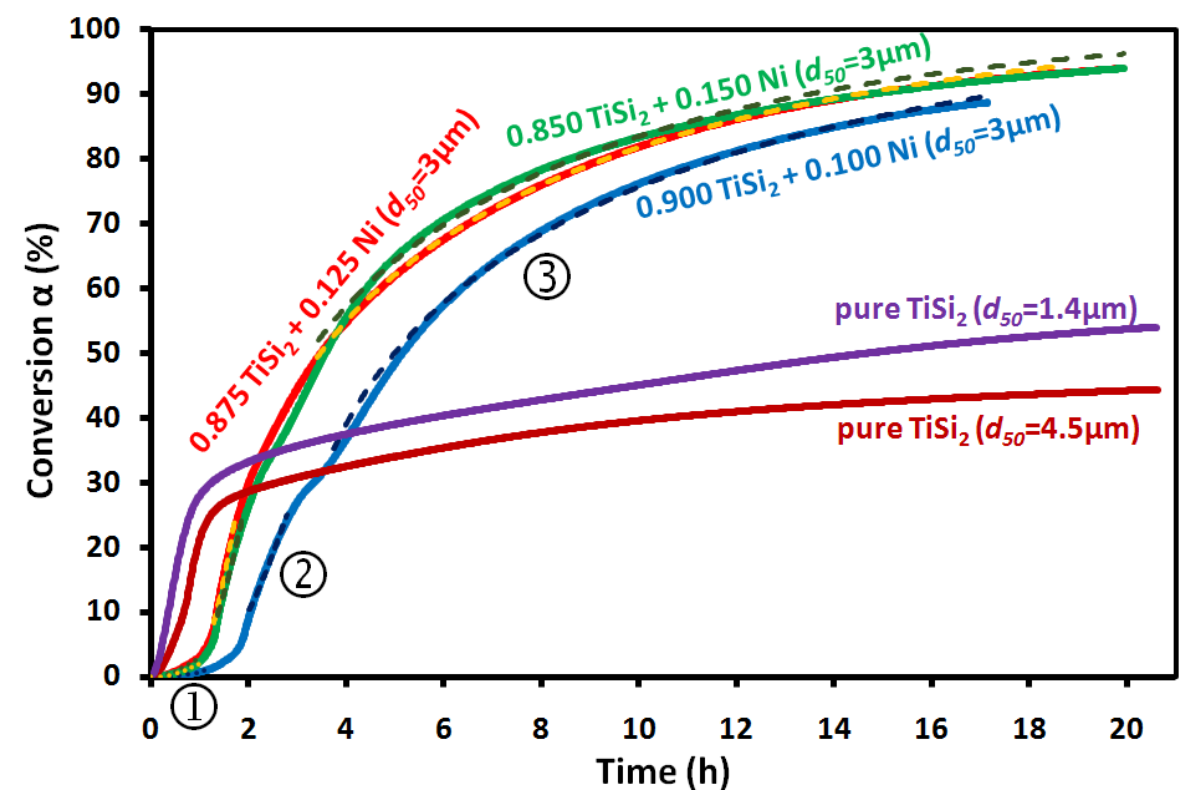

Figure 9: Mass conversion rate versus time at $1100^{\circ} \mathrm{C}$ of pure $\mathrm{TiSi}_{2}$ powder [29] in comparison to $(1-x) \mathrm{TiSi}_{2}+x$ Ni mixtures with $x=0.100 ; 0.125$ and 0.150 .

(fits of the three successive stages with the $A 2$ and $D 3$ models plotted in dot lines)

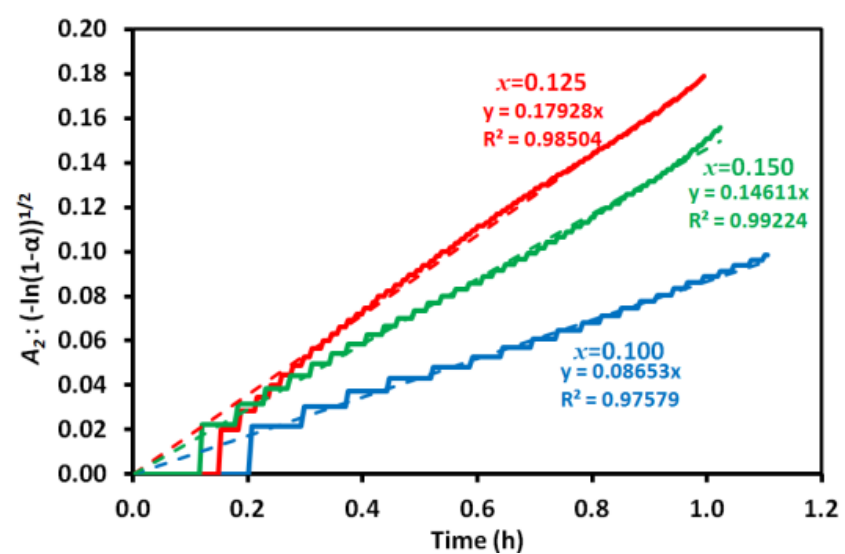

a)

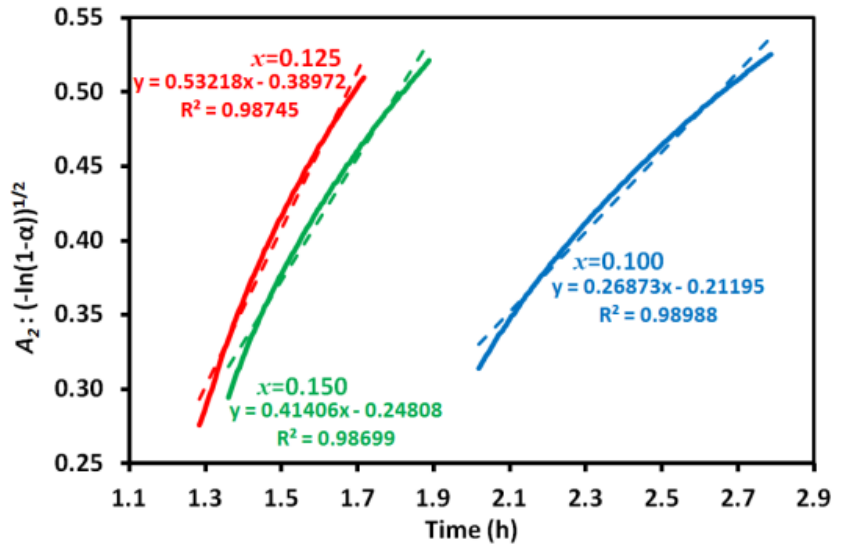

b)

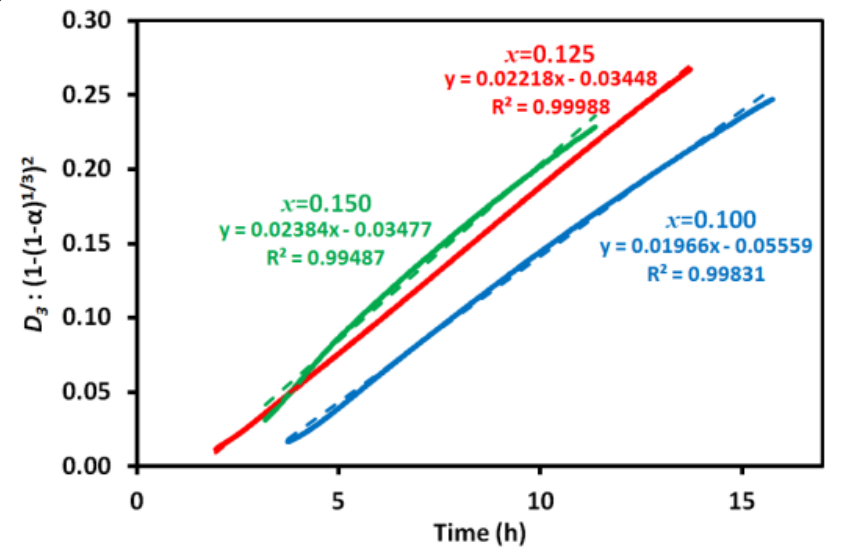

c)

Figure 10: $g(\alpha)=k . t$ plots and linear regressions of the compositions (1-x) TiSi $2+x$ Ni with $\mathrm{x}=0.100$; 0.125 and 0.150 at $1100^{\circ} \mathrm{C}:$ a) stage (1): $\mathrm{A}_{2}$ model, b) stage (2): $\mathrm{A}_{2}$ model, and c) stage (3): $\mathrm{D}_{3}$ model 

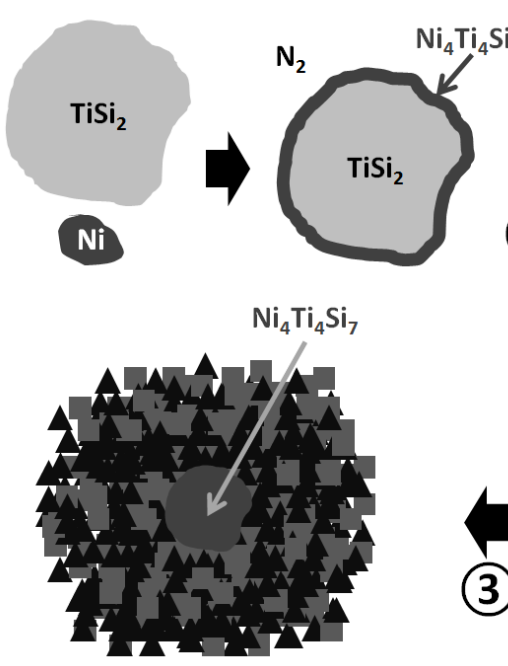

(3)

a)

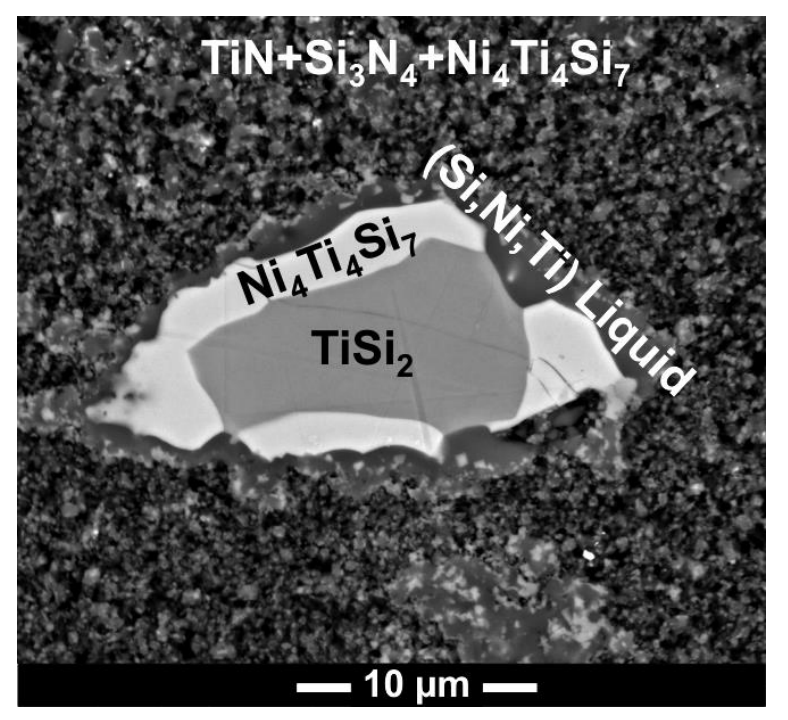

b)

Figure 11: Nitridation of a $\mathrm{TiSi}_{2}$ grain in presence of $\mathrm{Ni}$ :

a) proposed conversion mechanism with four successive steps and

b) backscattered electrons image of a large grain in the sample $0.900 \mathrm{TiSi}_{2}+0.100 \mathrm{Ni}$ treated at $1100^{\circ} \mathrm{C}$

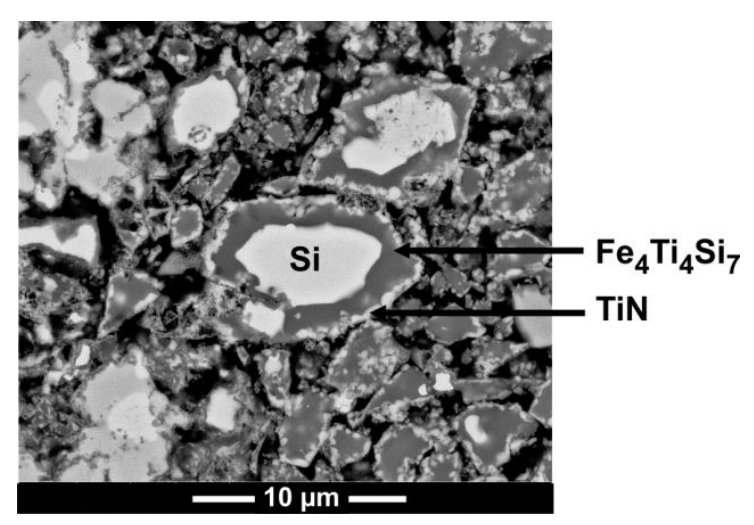

a)

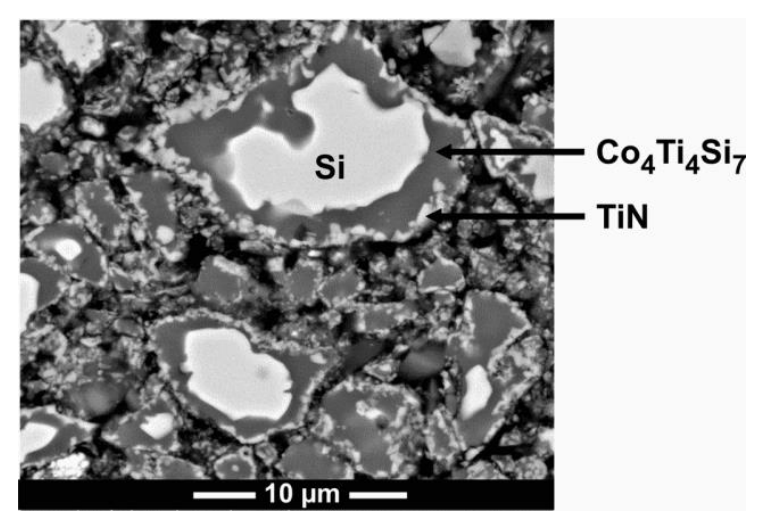

b)

Figure 12: Backscattered electrons images of a $\mathrm{TiSi}_{2}$ powder heat treated at $1100^{\circ} \mathrm{C}$ in nitrogen with addition of: a) $\mathrm{Fe}$ and b) $\mathrm{Co}$ 
Table 1: Nickel contents, theoretical volume gains, mass conversion and phases composition of the (1-

$x) \mathrm{TiSi}_{2}+x \mathrm{Ni}(0.000 \leq x \leq 0.250)$ compact samples heat treated at $1100^{\circ} \mathrm{C}$ for 40 hours

\begin{tabular}{|c|c|c|c|c|c|c|c|c|}
\hline \multirow{3}{*}{$\begin{array}{l}\text { Nickel content } \\
\qquad(x)\end{array}$} & \multirow{3}{*}{$\begin{array}{c}\text { Theoretical } \\
\text { volume gain } \\
\text { (\%) }\end{array}$} & \multirow{3}{*}{$\begin{array}{c}\text { Mass } \\
\text { conversion } \\
\alpha(\%)\end{array}$} & \multicolumn{6}{|c|}{ Phases detection from XRD and EDS analysis } \\
\hline & & & \multicolumn{6}{|c|}{ (detected: + ; undetected: -) } \\
\hline & & & TiN & $\mathrm{Si}_{3} \mathrm{~N}_{4}$ & Si & $\mathrm{TiSi}_{2}$ & $\begin{array}{l}\mathrm{NiSi} / \\
\mathrm{NiSi}_{2}\end{array}$ & $\mathrm{Ni}_{4} \mathrm{Ti}_{4} \mathrm{Si}_{7}$ \\
\hline $0.000[29]$ & 58.7 & 48.8 & + & + & + & + & & \\
\hline 0.025 & 56.8 & 77.5 & + & + & + & + & - & + \\
\hline 0.050 & 54.9 & 77.5 & + & + & + & + & - & + \\
\hline 0.075 & 82.9 & 87.0 & + & + & - & + & - & + \\
\hline 0.100 & 50.8 & 90.2 & + & + & - & - & - & + \\
\hline 0.125 & 48.6 & 96.0 & + & + & - & - & - & + \\
\hline 0.150 & 46.4 & 96.3 & + & + & - & - & - & + \\
\hline 0.175 & 44.0 & 88.8 & + & + & - & - & + & - \\
\hline 0.200 & 41.5 & 68.9 & + & + & - & - & + & - \\
\hline 0.250 & 36.2 & 53.1 & + & + & - & - & + & - \\
\hline
\end{tabular}

Table 2: Common kinetic models [46]

\begin{tabular}{|c|c|c|c|}
\hline & Kinetic models & $g(\alpha)$ & Code \\
\hline \multirow[t]{3}{*}{ Nucleation-growth } & Random nucleation and subsequent growth & {$[-\ln (1-\alpha)]^{1 / 2}=k . t$} & $A 2$ \\
\hline & Random nucleation and subsequent growth & {$[-\ln (1-\alpha)]^{1 / 3}=k . t$} & A3 \\
\hline & Random nucleation and subsequent growth & {$[-\ln (1-\alpha)]^{1 / 4}=k . t$} & A4 \\
\hline \multirow[t]{2}{*}{ Chemical reaction } & Phase boundary reaction, cylindrical symmetry & $1-(1-\alpha)^{1 / 2}=k . t$ & $R 2$ \\
\hline & Phase boundary reaction, spherical symmetry & $1-(1-\alpha)^{1 / 3}=k . t$ & R3 \\
\hline \multirow[t]{4}{*}{ Diffusion model } & One-dimensional diffusion & $\alpha^{2}=k . t$ & $D 1$ \\
\hline & Two-dimensional diffusion, cylindrical symmetry & {$[(1-\alpha) \cdot \ln (1-\alpha)]+\alpha=k . t$} & $D 2$ \\
\hline & Three-dimensional diffusion, spherical symmetry & {$\left[1-(1-\alpha)^{1 / 3}\right]^{2}=k . t$} & D3 \\
\hline & Three-dimensional diffusion, cylindrical symmetry & $1-(2 / 3) \cdot \alpha-(1-\alpha)^{2 / 3}=k . t$ & D4 \\
\hline
\end{tabular}

